\title{
NOVEL DESIGNS OF BROADBAND PATCH ANTENNA FOR WIRELESS COMMUNICATION APPLICATION (1800 MHZ AND $2400 \mathrm{MHZ})$
}

\author{
Melad Olaimat, Aws Al-Qaisi \\ Communication Technology Engineering Department, Faculty of Engineering \\ Technology \\ Al-Blaqa'a Applied University, Amman, Jordan
}

\begin{abstract}
In this paper, three novel designs of broadband patch antenna are proposed. The first design propose broadband slotted equilateral triangular patch antenna (ETPA) operating on frequency around $1800 \mathrm{MHz}$. The second design propose broadband slotted right angle isosceles triangular patch antenna RAITPA operating on frequency around $2400 \mathrm{MHz}$. The third design proposes wideband V-Slotted and shorted edge ETPA antenna operating on frequency around $2400 \mathrm{MHz}$. The two powerful software HFSS and IE3D are used to simulate the proposed designs. Very good agreement between HFSS and IE3D software is obtained. The designs were chosen to fit modern wireless communication applications operate at Industrial Scientific Medical (ISM) bands such as Wireless local area networks (WLAN). Moreover, mounting the patch on thick substrate with loaded slot technique and loading the patch with a notch technique were used to enhance the bandwidth of those designs. Hence, large fractional bandwidth is obtained.
\end{abstract}

\section{KEYWORDS}

Triangular microstrip antenna, slotted antenna, broadband antenna, notch antenna, wireless application, substrate

\section{INTRODUCTION}

Microstrip antennas consist of a patch of metallization on a grounded substrate. They are lowprofile, lightweight antennas, most suitable for aerospace and mobile applications. Microstrip antennas have matured considerable during the past 35 years, and many of their limitations have been overcome [1]. Many of the antenna applications for satellite links, mobile communications, and wireless local-area networks impose constraints on compactness, dual-frequency operation, frequency agility, polarization control, and radiation pattern control. These functions can be achieved by microstrip antennas, and hence these antennas are becoming more commonly used [1]. Among the shapes that attracted much attention lately is the triangular shaped patch antenna [2]-[13]. This is due to their small size compared with other shapes like the rectangular and circular patch antennas. It is well-known that microstrip antennas are very narrow band, about several percent for a typical bandwidth. Therefore, bandwidth enhancement is usually demanded for practical applications [14]. Thus, bandwidth enhancement is becoming one of the major design considerations for practical applications of microstrip antennas. To meet bandwidth 
requirement, many bandwidth-enhancement or broadband techniques for microstrip antennas have been recently reported [14]. Decreasing the quality factor of the microstrip antenna is an effective way of increasing the antenna's impedance bandwidth. This kind of bandwidthenhancement technique includes the use of a thick air or foam substrate. For feeding using a probe feed, a large reactance owing to the long probe pin in the thick substrate layer is usually a problem in achieving good impedance matching over a wide frequency range. To overcome this problem associated with probe-fed microstrip antennas, it was reported that by embedding a Ushaped slot in the patch, the impedance bandwidth of a probe-fed microstrip antenna with a thick air substrate can easily be enhanced [12]. In this paper, the designs are simulated using two powerful softwares. Wide range of frequencies is obtained. More enhancements obtained compared with previous designs. This paper can be divided into five sections. In Section II, broadband slotted equilateral triangular patch antenna (ETPA) is designed and simulated. This proposed design is used for Wireless Applications (around $1800 \mathrm{MHz}$ ). In Section III, broadband slotted right angle isosceles triangular patch antenna (RAITPA) is proposed. The proposed design will operate a round $2400 \mathrm{MHz}$ which is used for Wireless applications. In Section IV, wideband V-slotted and shorted edge ETPA for wireless communication applications (around $2400 \mathrm{MHz}$ ) is proposed and simulated. Section V presents the comparison between all proposed design and pinch mark design in [13]. In Section VI present a conclusion of all results.

\section{Broadband Slotted Equilateral Triangular Patch Antenna (ETPA) (AROUND $1800 \mathrm{MHz})$}

It was demonstrated that, loading the patch with a U-shaped slot will enhance the bandwidth [13]. Figure 1 shows a proposed ETPA, loaded with slots. In this design, two techniques are exploited to obtain broadband operation. In the first technique the patch on thick substrate is mounted with loaded slot. In the second technique the patch is loaded with a notch which enhances the bandwidth. By combining both techniques, a broadband antenna that operates in frequencies ranging from $1530 \mathrm{MHz}$ to $1870 \mathrm{MHz}$ is obtained as shown in Figure 2. It can be seen from Figure 2 that the proposed design has a bandwidth of $340 \mathrm{MHz}$, and a center frequency of 1700 $\mathrm{MHz}$, which implies that a fractional bandwidth of $20 \%$ can be obtained. Moreover, it can be noted that this design can fit wireless communication application.

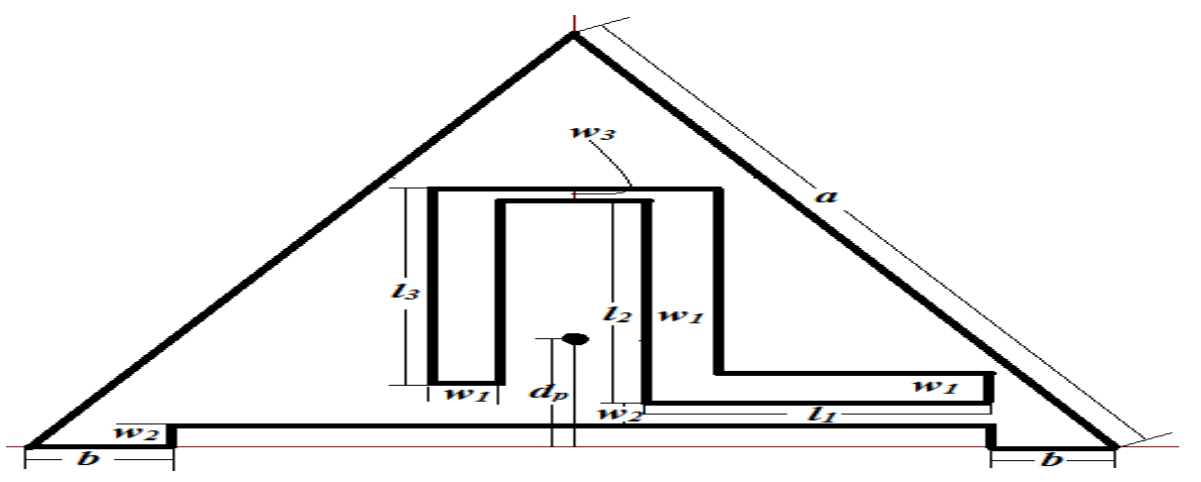

Figure 1: Geometry of our proposed broadband slotted ETPA; $a=9.1 \mathrm{~cm}, \mathrm{~h}=1.43 \mathrm{~cm}, \epsilon_{\mathrm{r}}=1.07, \mathrm{~d}_{\mathrm{p}}=2.125 \mathrm{~cm}$, $\mathrm{w}_{1}=0.6 \mathrm{~cm}, \mathrm{w}_{2}=0.4 \mathrm{~cm}, \mathrm{w}_{3}=0.25 \mathrm{~cm}, l_{1}=2.85 \mathrm{~cm}, l_{2}=3.89 \mathrm{~cm}, l_{3}=3.72 \mathrm{~cm}$, and $\mathrm{b}=1.05 \mathrm{~cm}$. 
International Journal of Computer Networks \& Communications (IJCNC) Vol.7, No.3, May 2015

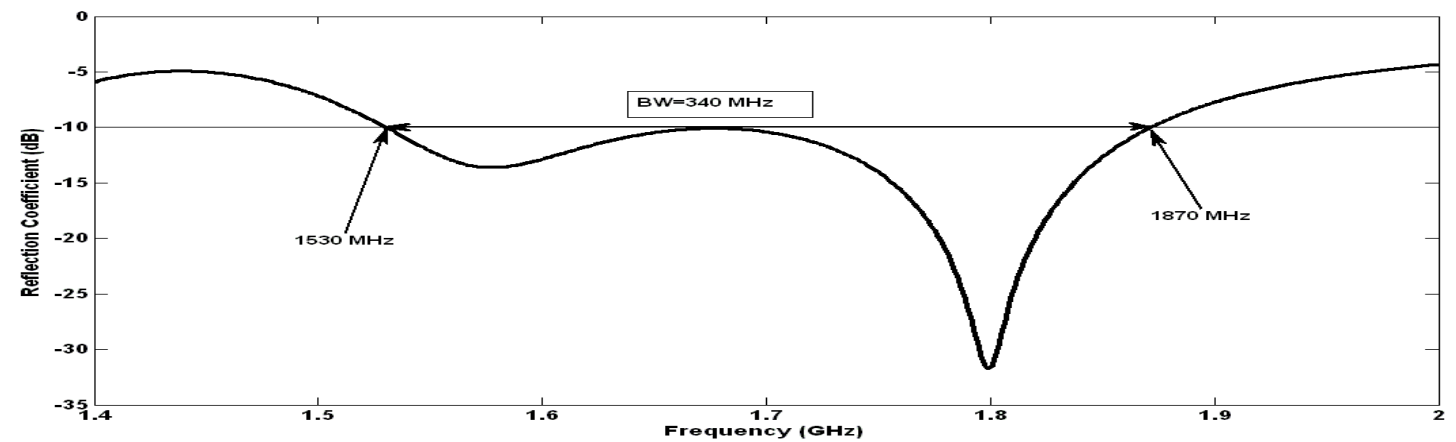

Figure 2: Simulated reflection coefficient of our proposed design shown in Figure 1 [IE3D].

For the sake of justification, this design is simulated again using HFSS simulator as shown in Figure 3. It can be noted from Figure 4 that a very good agreement between both simulators is obtained

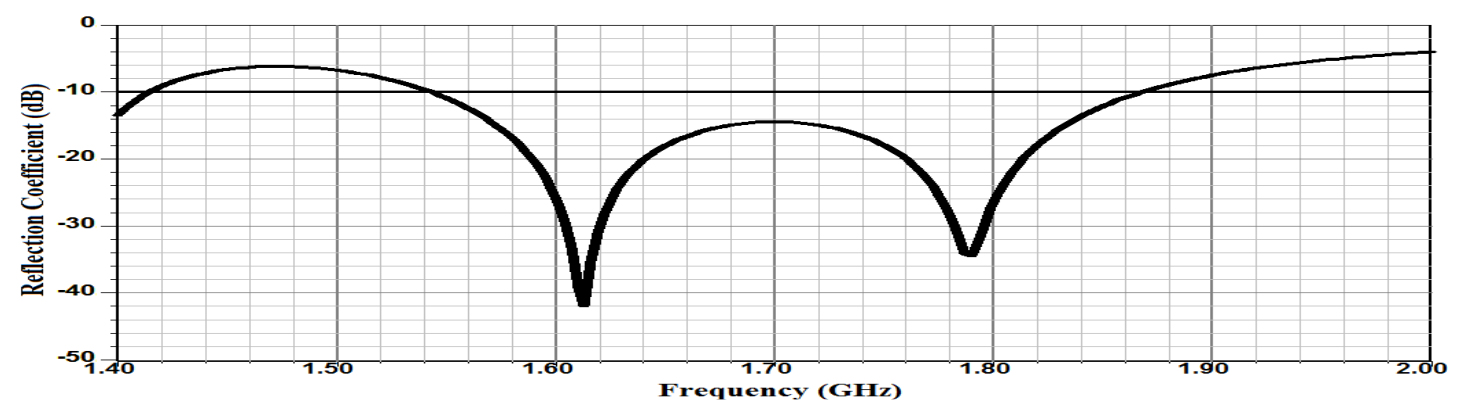

Figure 3: Simulated reflection coefficient of our proposed design shown in Figure 1 [HFSS].

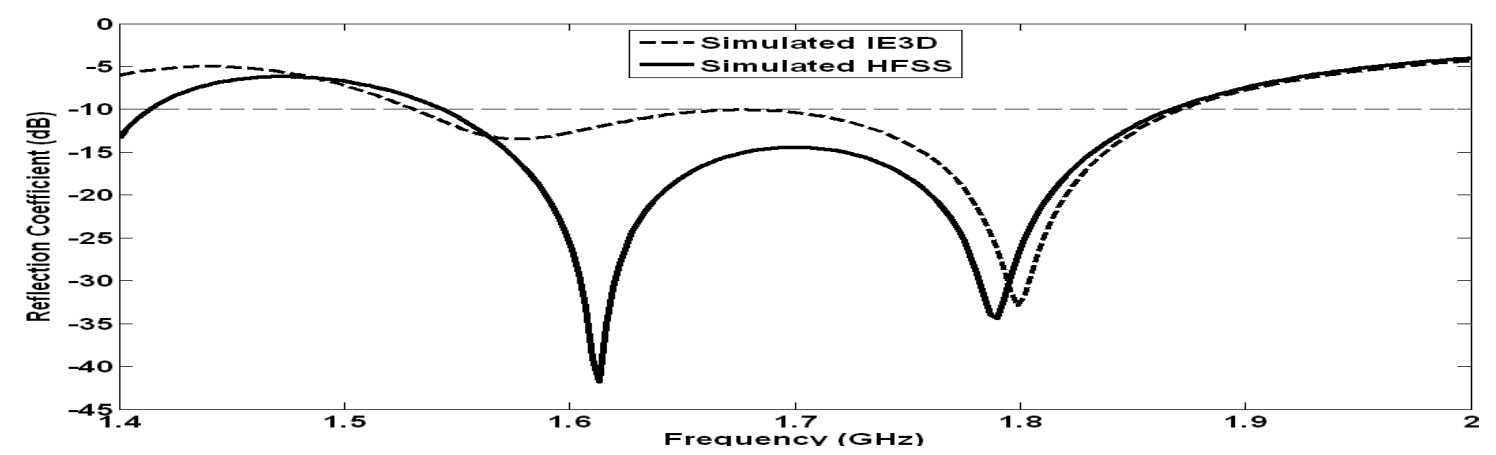

Figure 4: Comparison between HFSS and IE3D results for the design shown in Figure 1.

For the sake of justification, the radiation pattern of this design is studied at three different frequency values within the operating band. Specifically, Figures 5-7 show the radiation patterns at $1575 \mathrm{MHz}, 1680 \mathrm{MHz}$, and $1800 \mathrm{MHz}$. It can be noted that the pattern is almost the same at the three frequencies. In these figures, the beam in the $\Phi=90$ o plane gets a bit tilted from broadside as the frequency increases. 


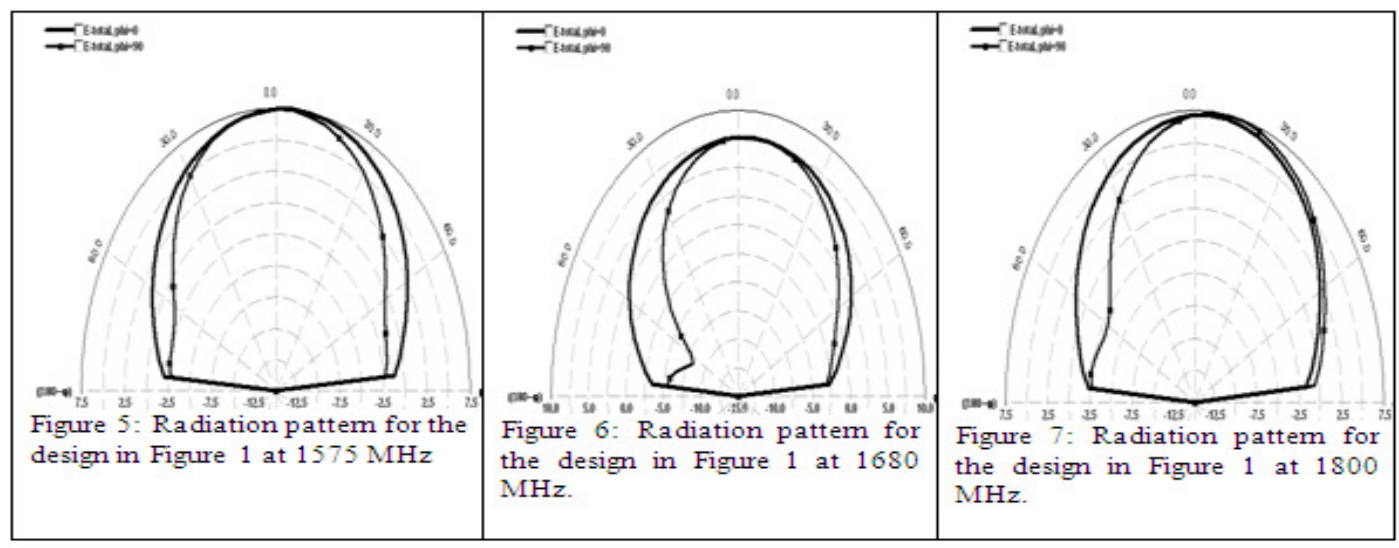

\section{Broadband Slotted Right Angle Isosceles Triangular Patch ANTENNA RAITPA FOR WIRELESS APPLICATIONS (AROUND $2400 \mathrm{MHz}$ )}

Another broadband patch antenna is proposed to fit with the bands of wireless communication applications. The proposed antenna is a RAITPA loaded with slots, mounted on a thick foam substrate $(\mathrm{Cr}=1.07)$, and fed, using probe-feed at dp as shown in Figure 8.

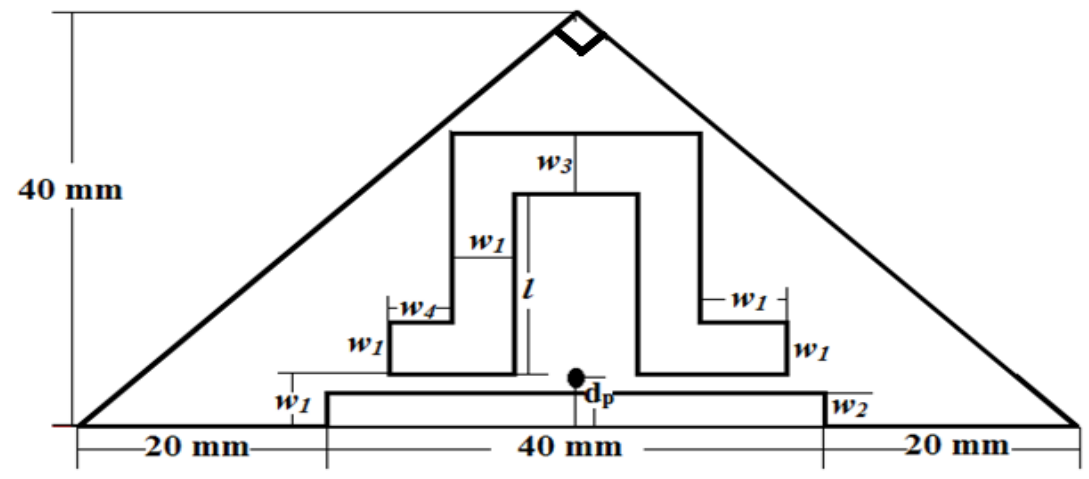

Figure 8: Geometry of the proposed broadband slotted RAITPA; $\mathrm{h}=14.3 \mathrm{~mm}, \mathrm{C}_{\mathrm{r}}=1.07, w_{1}=5 \mathrm{~mm}, w_{2}=3$ $\mathrm{mm}, w_{3}=6 \mathrm{~mm}, w 4=4 \mathrm{~mm}, l=17.5 \mathrm{~mm}$, and $\mathrm{d}_{\mathrm{p}}=5 \mathrm{~mm}$.

From Figure 9, it can be seen that this patch operates at frequencies ranging from $2463 \mathrm{MHz}$ to $2948 \mathrm{MHz}$, with bandwidth equal to $485 \mathrm{MHz}$. Again, this design is simulated using HFSS simulator for the sake of justification. 


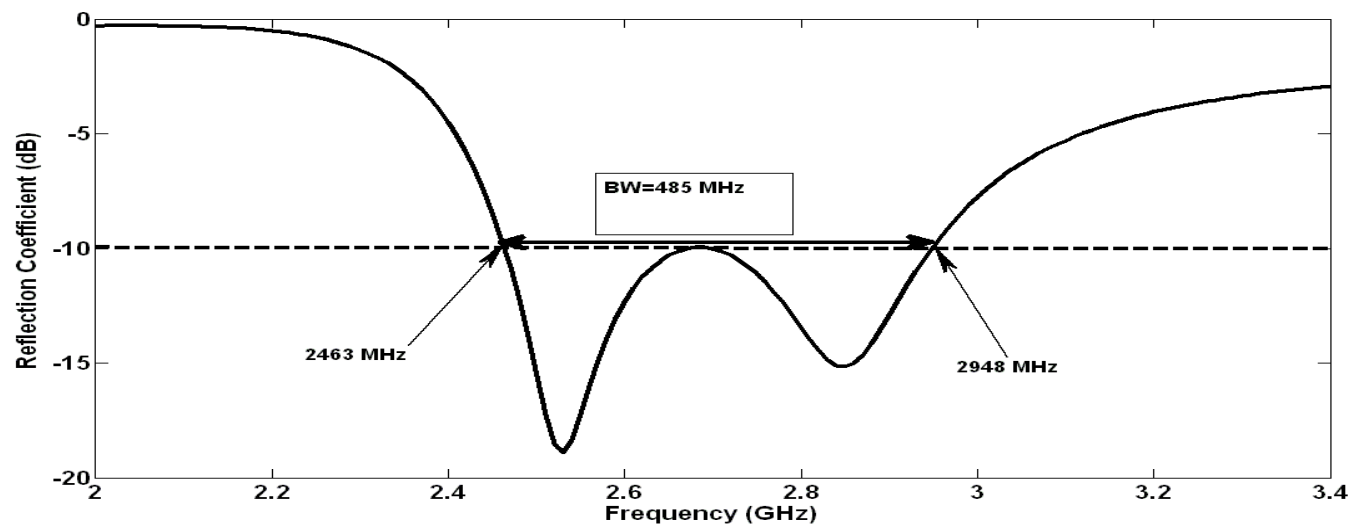

Figure 9: Simulated reflection coefficient of our proposed design shown in Figure 8 [IE3D].

Figure 10 shows the simulated reflection coefficient using HFSS. The obtained results, using both simulators, are close to each other as shown in Figure 11.

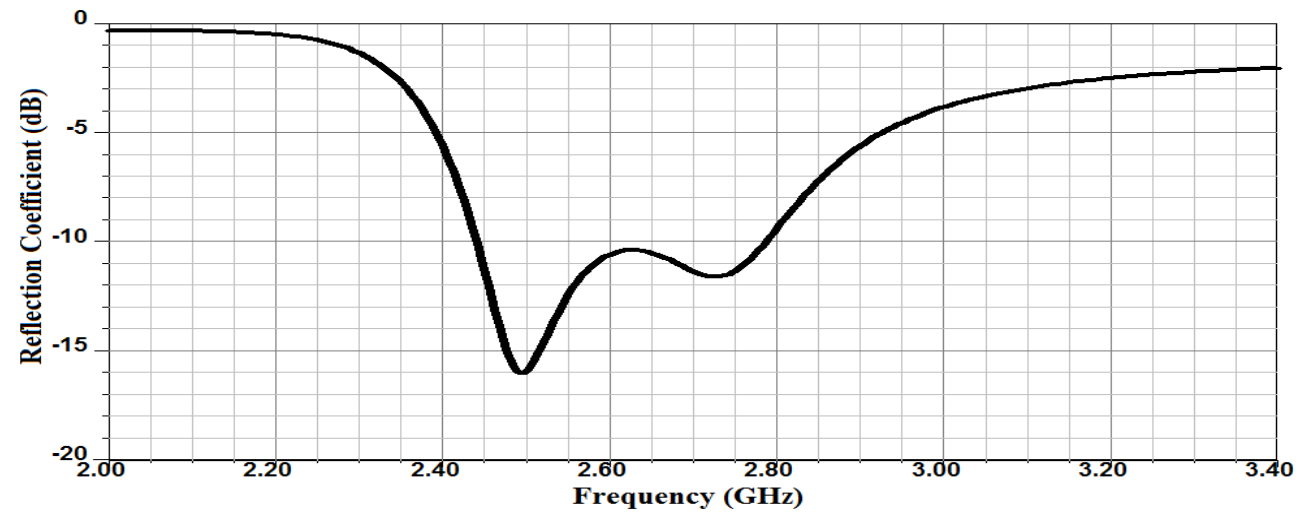

Figure 10: Simulated reflection coefficient of our proposed design shown in Figure 8 [HFSS].

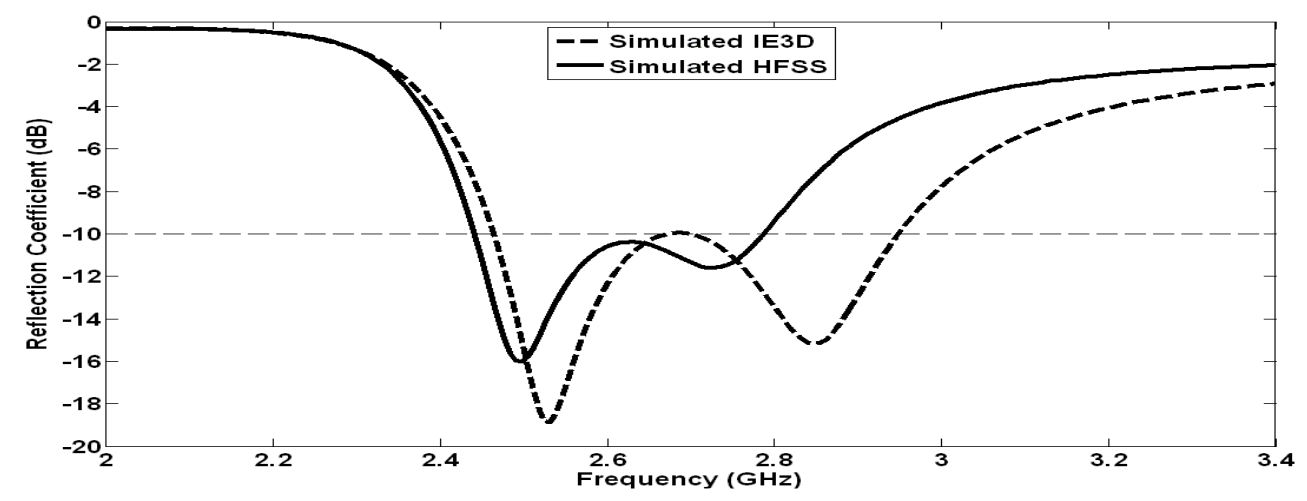

Figure 11: Comparison between HFSS and IE3D results for design shown in Figure 8. 
The radiation pattern of this design is studied at three different frequencies. From Figures 12-14, it can be noted that the pattern is almost the same at the three frequencies. In these figures, the beam in the $\Phi=90$ o plane gets a bit tilted from broadside as the frequency increases.

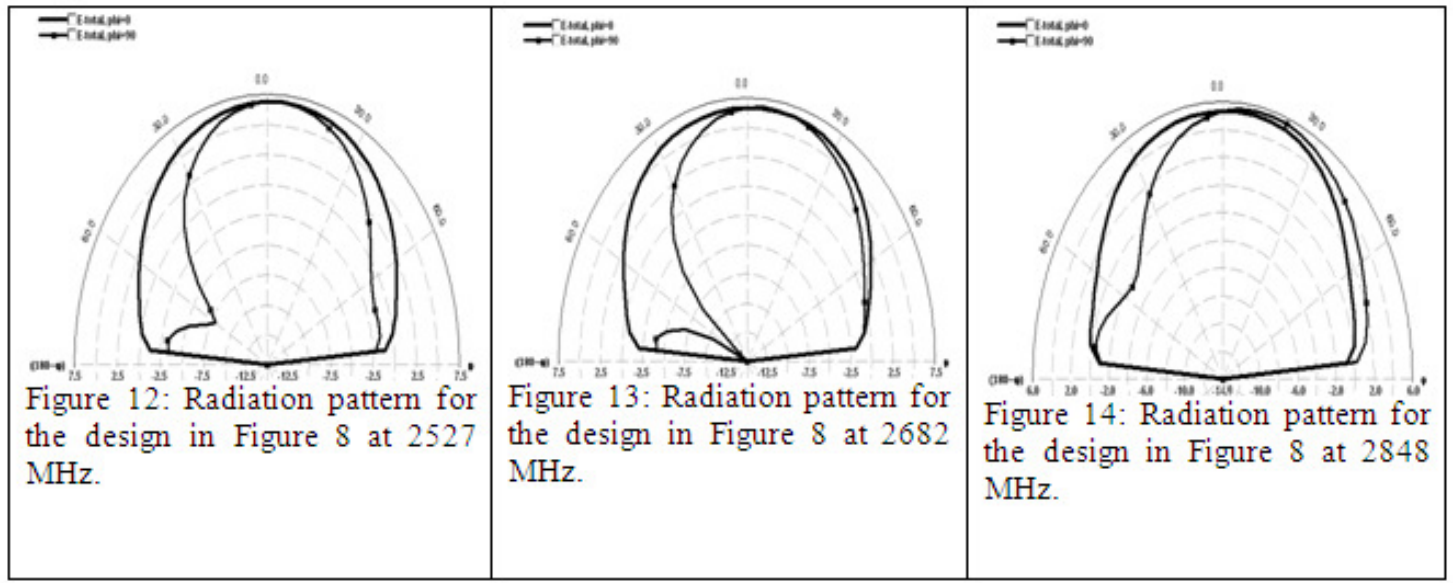

\section{Proposed Wideband V-Slotted ANd Shorted Edge ETPA ANTENNA FOR WiRELESS COMMUNICATION APPLICATIONS (AROUND 2400 MHz)}

A new design of Wideband V-Slotted and Shorted Edge ETPA Antenna is proposed for Wireless Communication Applications. Figure 15 shows the geometry of the design. In this design, two techniques are combined. Namely, shorting the edge and loading V-slots on the patch. This combination allows obtaining a wideband antenna that operates at frequencies ranging from 2070 MHz to $2714 \mathrm{MHz}$, with bandwidth equal to $644 \mathrm{MHz}$, and center frequency equal to $2392 \mathrm{MHz}$, as shown in Figure 16. So, a fractional bandwidth of approximately $27 \%$ can be achieved. It can be noted that this design can be used for wireless communication applications, especially, WLANs and ISM, which operate at frequencies ranging from $2400 \mathrm{MHz}$ to $2484 \mathrm{MHz}$.

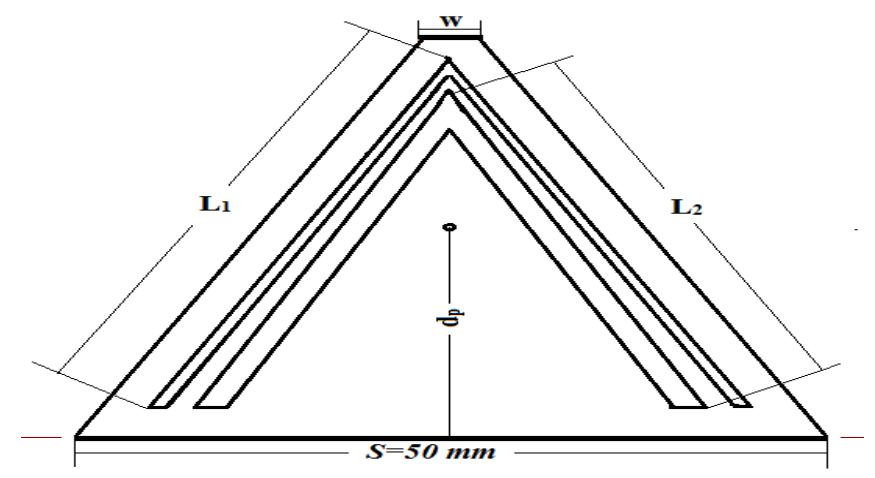

Figure 15: Geometry of our proposed wideband V-slotted ETPA; $\mathrm{h}=6 \mathrm{~mm}, \epsilon_{\mathrm{r}}=4.6, w=3.8$ 


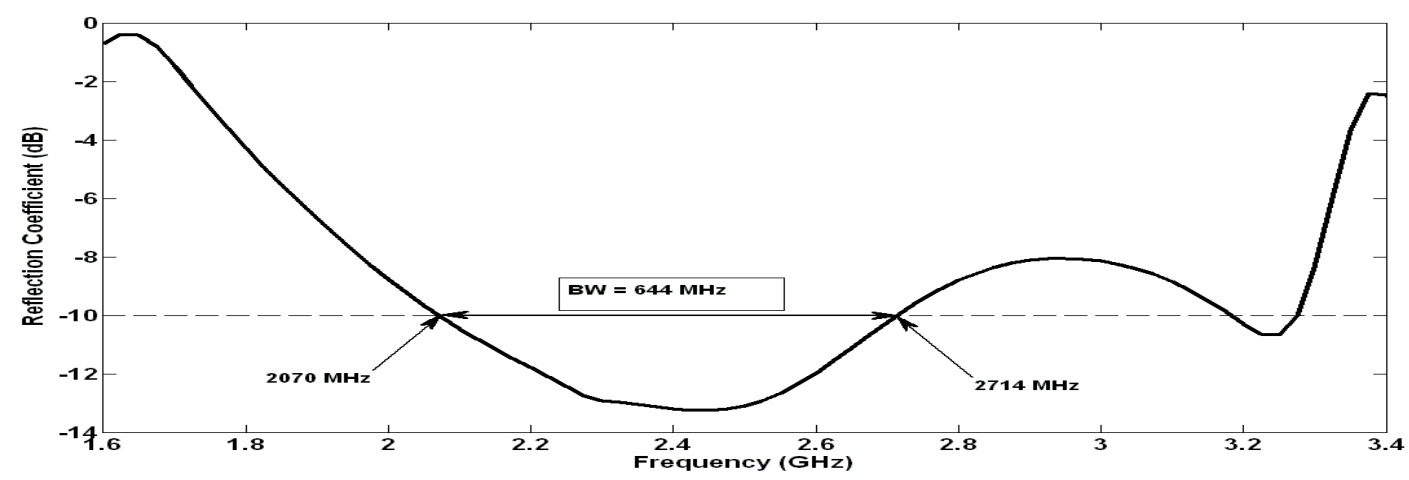

Figure 16: Simulated reflection coefficient of the design shown in Figure 15 [IE3D].

The radiation pattern of this design is studied at three different frequencies. From Figures 17-19, it can be noted that the pattern is almost the same at the three frequencies. The radiation is in the broadside direction in the $\Phi=0$ o plane, while it is titled approximately 450 in the $\Phi=90$ o plane.

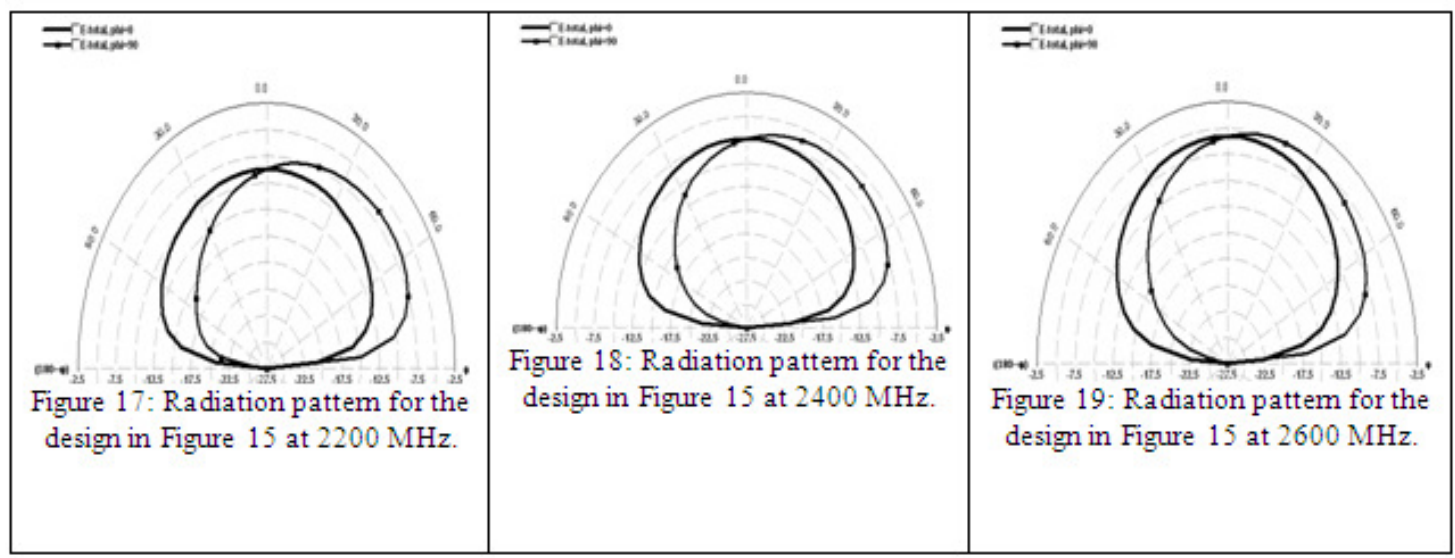

\section{COMPARISON}

Figure 20 shows a comparison between result obtained from reference [13] and result obtained from proposed design in figure 1 . As shown in the figure more bandwidth can be obtained in the proposed design. It can be seen that the proposed design has a bandwidth of $340 \mathrm{MHz}$, and a center frequency of $1700 \mathrm{MHz}$, which implies that a fractional bandwidth of $20 \%$ can be obtained, whereas the obtained bandwidth in [13] is $308 \mathrm{MHz}$ and a center frequency of 1677 $\mathrm{MHz}$, which implies that a fractional bandwidth of $18.3 \%$. It can be noted, first proposed design is better than the design proposed in [13] in terms of bandwidth and fractional bandwidth. 
International Journal of Computer Networks \& Communications (IJCNC) Vol.7, No.3, May 2015

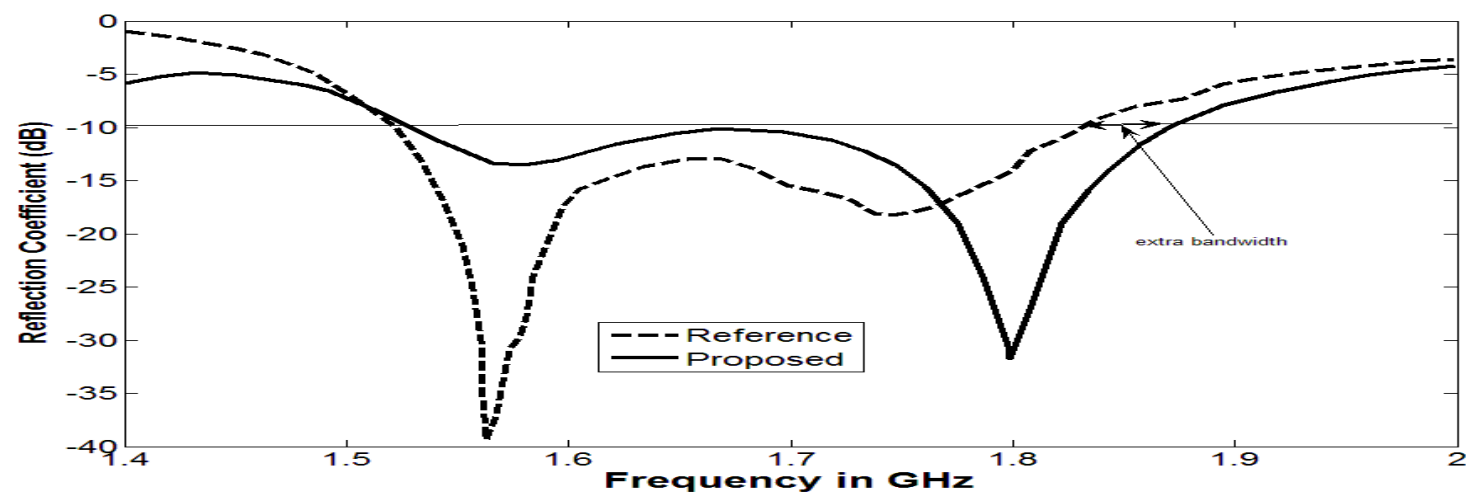

Figure 20: Comparison between result obtained from reference [13] and result obtained from proposed design in figure 1.

Figure 21 shows a comparison between results obtained from second and third proposed designs. It can be depicted that both designs are operated around $2400 \mathrm{MHz}$. Moreover, by using ETPA, more bandwidth can be obtained.

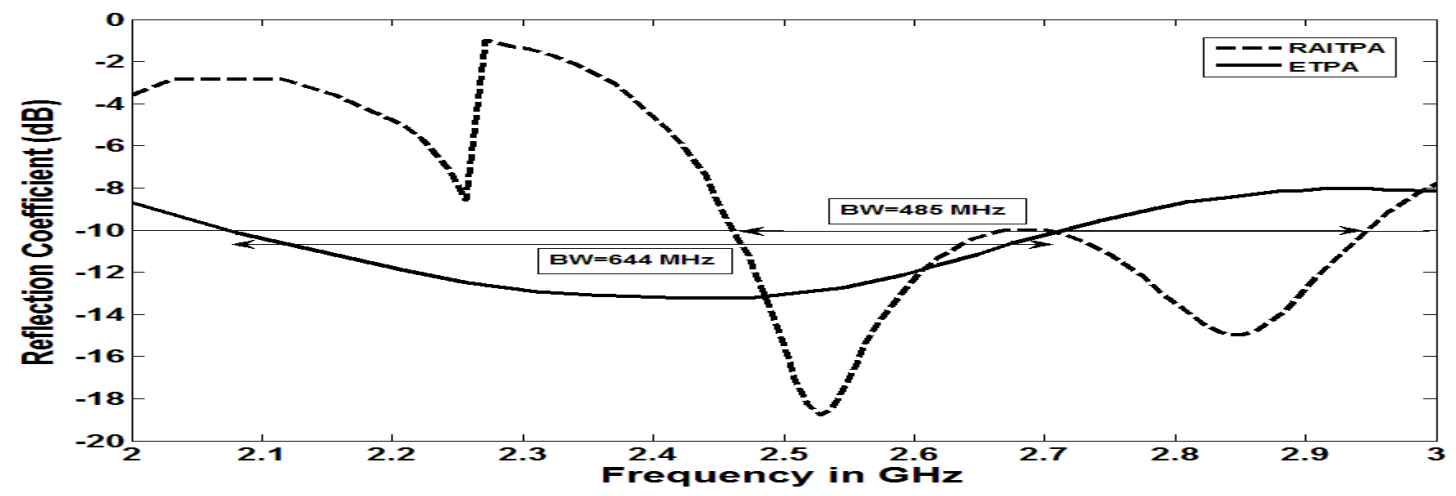

Figure 21: Comparison between results obtained from second and third proposed designs.

Table 1 shows a center frequency, bandwidth and fractional bandwidth for all designs which summarize all the results mentioned above.

Table 1: Comparison of Center frequency, bandwidth and fractional bandwidth for all designs.

\begin{tabular}{|c|c|c|c|}
\hline Design & $\begin{array}{c}\text { Center } \\
\text { Frequency } \\
\left(\mathbf{f}_{\mathbf{c}}\right) \\
(\mathbf{M H z})\end{array}$ & $\begin{array}{c}\text { Bandwidth } \\
(\mathbf{B W}) \\
(\mathbf{M H z})\end{array}$ & $\begin{array}{c}\text { Fractional } \\
\text { Bandwidth } \\
\left(\mathbf{B W} / \mathbf{f}_{\mathbf{c}}\right) * 100 \%\end{array}$ \\
\hline $\begin{array}{c}\text { Reference } \\
{[13]}\end{array}$ & 1677 & 308 & $18.3 \%$ \\
\hline $1^{\text {st }}$ Design & 1700 & 340 & $20 \%$ \\
\hline $2^{\text {nd }}$ Design & 2705.5 & 480 & $17.9 \%$ \\
\hline $3^{\text {rd }}$ Design & 2392 & 644 & $27 \%$ \\
\hline
\end{tabular}


International Journal of Computer Networks \& Communications (IJCNC) Vol.7, No.3, May 2015

\section{CONCLUSION}

In this paper, three new designs that fit modern wireless communication application, which operate at $1800 \mathrm{MHz}$ and $2400 \mathrm{MHz}$, are suggested and simulated using powerful software. The design is justified by comparing between two software tools (HFSS and IE3d) results and great agreement is obtained. Good result obtained compared with those obtained in [13]. Wider bandwidth is obtained which can be fit for new generations of wireless communication that require wider bandwidth.

\section{REFERENCES}

[1] R. Garg, P. Bhartia, I. J. Bahl, and P. Ittipiboon, Microstrip Antenna Design Handbook, Artech House, Boston. London, 2001.

[2] M. M. Olaimat and N. I. Dib, A Study of 15-75o-90o Angles Triangular Patch Antenna," Progress In Electromagnetics Research (PIER), Vol. 21, 2011, pp. 1-9.

[3] M. M. Olaimat and N. I. Dib, Improved Formulae for the Resonant Frequencies of Triangular Microstrip Patch Antennas, International Journal of Electronics, Vol. 98, No. 3, March 2011, pp. 407424.

[4] J. S. Dahele and K. F. Lee, On the Resonant Frequencies of the Triangular Patch Antenna, IEEE Trans. Ant. Propagat., Vol. AP-35, No. 1, Jan. 1987 pp. 100-101.

[5] J. Helszajn and D. S. James, "Planar Triangular Resonator with Magnetic Walls," IEEE Trans. on Microwave Theory and Techniques, Vol. MTT-26, 1978, pp. 95-100.

[6] D. Karaboga, K. Guney, A. Kaplan, and A. Akdagli, A New Effective Side Length Expression Obtained Using a Modified Tabu Search Algorithm for the Resonant Frequency of a Triangular Microstrip Antenna, Int J RF and Microwave CAE, Vol. 8, Issue 1, Dec. 1998, pp. 4-10.

[7] I. J. Bahl and P. Bhartia, Microstrip Antennas, Artech House, Dedham, MA, Chap. 4, 1980.

[8] W. Chen, K. F. Lee, and J. S. Dahele, "Theoretical and Experimental Studies of the Resonant Frequencies of the Equilateral Triangular Microstrip Antenna," IEEE Trans. Ant. Propagat., Vol. AP40, No. 10, Oct. 1992, pp. 1253-1256.

[9] R. Garg and S. A. Long, An Improved Formula for the Resonant Frequency of the Triangular Microstrip Patch Antenna, IEEE Trans. Ant. Propagat., Vol. AP-36, 1988, p. 570.

[10] Nasimuddin, K. Esselle, and A. K. Verma, Resonant Frequency of an Equilateral Triangular Microstrip Antenna, Microwave and Optical Technology, Vol. 47, No. 5, Dec 2005, pp. 485-489

[11] D.Guha and J.Y. Siddiqui, Resonant frequency of equilateral triangular microstrip patch antenna with and without air gaps, IEEE Trans. Antennas Propagate, vol. 52, no.8, Aug. 2004, pp. 2174-2177.

[12] Wong K, Compact and Broadband Microstrip Antennas, John Wiley \& Sons; 2002.

[13] Kin-Lu W, and Wen-Hsiu H. Broadband Triangular Microstrip Antenna with U-Shaped Slot, Electronic Letters, vol. 33, 1997, pp. 2085-2087

[14] R. Mudgal and L. Shrivastava, "Study of compact and wideband microstrip U-slot patch antenna with DGS for satellite applications" International Journal of Advanced and Innovative Research, Vol. 3, 2014, pp. 54-56 